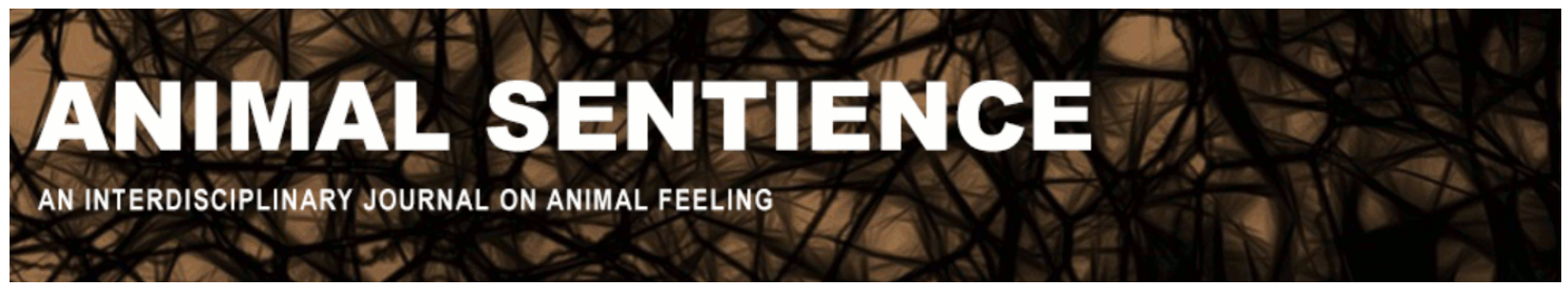

Hawkins, Ronnie Z. (2020) Thinking longer, looking deeper. Animal Sentience 30(26)

DOI: $10.51291 / 2377-7478.1657$

Date of submission: 2020-11-03

Date of acceptance: 2020-12-06

(c)

This article has appeared in the journal Animal

Sentience, a peer-reviewed journal on animal

cognition and feeling. It has been made open access,

free for all, by WellBeing International and deposited

in the WBI Studies Repository. For more information,

please contact

wbisr-info@wellbeingintl.org.

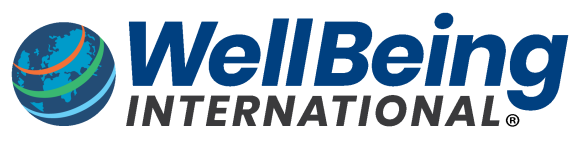

SOLUTIONS FOR PEOPLE, ANIMALS AND ENVIRONMENT 


\title{
Thinking longer, looking deeper
}

Commentary on Wiebers \& Feigin on Covid Crisis

\author{
Ronnie Z. Hawkins \\ Department of Philosophy, University of Central Florida
}

\begin{abstract}
We need to situate the present crisis within the larger context of what we humans have done to the nonhuman forms of life with which we evolved, taking a longer view of our own evolutionary origins and a deeper look at what might be a more appropriate role for our species to play within the Biosphere.
\end{abstract}

Ronnie Hawkins taught environmental philosophy, bioethics, philosophy of science, and existentialism at the University of Central Florida for many years. Her concerns center around the devastating impact that our human species is having on the Biosphere and exploring ways we might stop and reverse that runaway train.

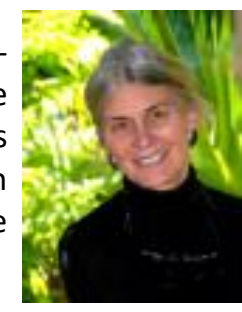

I hope our society will take the advice of Wiebers \& Feigin (2020) and "reflect deeply" upon what the Covid crisis is telling us about our species' role, not only in relation to such events but within the Biosphere as a whole, both as the form of life we evolved to be and as the one that we have become; we do need to "rethink our relationship with all life on this planet," learn to appreciate "the profound interconnectedness of all life," and incorporate respect for that life in our ethics and our practices. If you've been living within the common belief bubble all these years, however, the enormity of what we humans have done to the other species with which we once shared the planet is hard to grasp. I can only agree with Lee (2020) that if the COVID crisis awakens us from our slumber and causes us to change our ways, we and these other lifeforms will indeed "have been given a gift."

1. The Human Usurpation of the Wild. We humans, collectively, have usurped natural habitat and diminished native species to an astonishing degree, replacing wild animals with domestic livestock, commodifying those that remain, and converting their wild habitats into vast agroindustrial monocultures-practices that are believed to be precipitating causes of the Covid crisis.

Most people seem to have very little awareness of the extent of this problem, however, or of the state of the actual biological world they live in. Courchamp et al. (2018) recently identified what a sampling of the public considered the "ten most charismatic animals," including the lion, the tiger, the elephant, the giraffe, the cheetah, and the gorilla; when asked what they knew about their conservation status; less than half of people queried were aware that their favorite animal is now classified as either Vulnerable, Endangered, or Critically Endangered of becoming extinct in the wild within the not so distant future. These researchers also had a group of volunteers record every time they encountered one of these ten animals in logos, advertisements, entertainment, stuffed toys, and so on- "virtual animals" - over the course of a 
week, and found that they were seeing them several hundred times a month. They concluded that the public perception was being shaped, not by the presence of living animals, but by the ubiquity of our human representations of certain animals, leading us to believe, erroneously, that all's right with these animals' worlds (and the natural world as a whole).

Unfortunately, it's not. The Biosphere is badly out of balance with respect to anything that could be considered a fair and equitable division of space and resources among the evolutionary cohorts that together embarked upon the Quaternary period of planetary history, and our one species seems to have been the orchestrator, and continues to be the ongoing perpetrator, of the growing imbalance. Most of the large animals that were present at the start of the Pleistocene epoch were extinct by its end, and the emergence of Homo sapiens about 200,000 years ago is believed to have been a major force in their disappearance (Koch and Barnosky 2006). It is, however, the tremendous growth of our collective destructive power over the course of human history-in particular, its acceleration over recent decades as interconnecting anthropogenic processes go exponential-that's plunging us ever deeper into a seemingly bottomless extinction event, already making an identifiable mark on the geological record. An astounding statistic exposes the existential situation in stark relief: recent estimates (Bar-On, Phillips and Milo 2018) are that the total biomass of all the remaining wild mammals on Earth is equal to no more than about $4 \%$ of the biomass of humans plus our domesticated food animals. When the great whales and other marine mammals are excluded, moreover, the total biomass of all the land mammals left in the wild, worldwide, is only about $5 \%$ of the biomass of all of us humans taken together, and it makes up less than $2 \%$ of the biomass of us plus our livestock.

The proximal causes of all this wild animal destruction are many and varied. Some of it is climate change: polar bears are drowning, others starving to death as the sea ice-their hunting grounds-dwindles and disappears. Meanwhile terrestrial habitats go up in flames because of hot, dry conditions, estimates being that at least one billion wild mammals, birds and reptiles perished in the Australian fires this year (Lewis 2020, Pickrell and Pennisi 2020). Others are losing ground because food webs are fraying around the world, with declining insect populations on land, largely attributed to industrial agriculture (Seibold et al. 2019), and a loss of bottom-of-thefood-chain krill and other plankton in the oceans, due to overharvesting plus, increasingly, shelldissolving ocean acidification as atmospheric CO2 levels continue to rise (Hannibal 2020, Feely et al. 2004, Orr et al. 2005). But the desperate straits of most of the "charismatic" mammals examined by Courchamp et al. can usually be connected fairly directly to our human appetites. Most of the world's large animals - its "megafauna" - are being squeezed right out of existence. They are caught between the pincers of habitat encroachment-increasingly for agroindustrial monocultures of crops to feed livestock imprisoned in Concentrated Animal Feeding Operations (CAFOs) - on the one side, and human hunters on the other, scouring remaining habitat, funneling survivors into increasingly lucrative global markets for pets, bushmeat, and animal parts (Machovina, Feeley and Ripple, 2015; Ripple et al. 2016; Ripple et al. 2019). It is apparently out of this unholy nexus that the Covid crisis was generated.

Faust et al. (2018) have developed a model of pathogen transmission resulting from habitat destruction that helps us visualize how a "spillover" of disease organisms from wild animal populations into human populations can take place. Wild species naturally carry many viruses, bacteria and other organisms that may or may not be pathogenic for them. When they 
live in habitat free from human encroachment these organisms pose no disease risk to human populations. When humans begin to cut into wild animal habitat, however, and convert the land into agricultural spreads or human habitation, it creates an "edge" with the remaining habitat, interfering in various ways with the requirements of "core" species (this is known ecologically as the "edge effect"). This compresses and stresses the animals that remain and often installs nonnative species (humans and/or their domestic animals) on the other side of this "edge," species potentially vulnerable to any pathogens the wildlife might be carrying.

Faust et al. depict the effect on the "edge" -- the interface between the two types of land use with progressive enlargement of the anthropogenically altered area. They use the length of the "edge" as a proxy for interspecies contact. Different sorts of transmission are considered, but the overall finding is that the highest probability of pathogen spillover triggering a disease outbreak occurs when about half of the original habitat has been destroyed. This is the point where the "edge" reaches its greatest extent, with sizeable populations on either side of it. Sufficient wild animals remain to carry potential pathogens and relatively large populations of humans and/or livestock can become the new hosts. The likelihood of transmission lowers as wild populations dwindle and disappear, but if spillover does occur as they vanish, it risks creating the largest outbreak, because the pool of susceptible hosts is approaching its maximum.

If huge swaths of habitat are liquidated in one fell swoop, of course, their wildlife and potential pathogens may be eliminated at the same time. But Faust et al. recognize the value of biodiversity and emphasize the importance of conserving large blocks of intact habitat that preserve the integrity of core areas and minimize "edge." The ethical question that arises-in light of our realization of the degree to which our species has already overtaken wild nonhuman species and their habitats and the injustice, let alone the foolhardiness, of our having done sois, of course, how to stop this seemingly relentless onslaught (largely driven these days by "investment") into remaining habitat and the commodification of its remaining inhabitants (Treves et al. 2019). A long-term goal will be reversing the direction of this biospherically destructive process.

Phasing out and eventually closing down the markets for wild animals and their body parts-the demand for which appears to have skyrocketed over the last several decadespresents another set of problems. Redford $(1992,412)$ was able to write that "until recently," human influence on tropical forests through such activities as hunting was regarded by ecologists to be, in most cases, "negligible," and he pointed out, as if for the first time, that "a forest can be destroyed by humans from within as well as from without." A few years later it was estimated that somewhere between 67,000 and 164,000 metric tons of wild meat were being consumed in the Brazilian Amazon every year, and that more than a million metric tons of wild meat were being taken out of the tropical forests in Africa (Robinson, Redford and Bennett 1999); a few years after that it was being acknowledged that "massive overhunting of wildlife for meat across the humid tropics is now causing local extinctions of numerous species" (Milner-Gulland and Bennett 2003). But the public's first introduction to the problem was probably the photography of Karl Ammann, whose full-color documentation of the problem (Rose et al. 2003, Peterson 2004), showing the heads of some of our great ape cousins in cooking pots and bundles of bushmeat being smuggled out of African forests on logging trucks, opened our eyes. Similar patterns of exploitation were also emerging in Asia. Continuing human population growth in areas surrounding biodiversity "hotspots" globally has been substantially higher than in the world 
as a whole (Cincotta, Wisnewski and Engelman 2000), and is particularly problematic for surviving nonhuman populations because human populations in these areas are often already suffering from economic marginalization and look to the wild animals as an important food source.

Piling threat upon threat for the animals, moreover, local people have begun improving their own lot by feeding the growing international appetite for body parts; for an in-depth look at an extreme example, sensitive to the needs of variously positioned actors, see Annette Hubschle's (2016) dissertation examining the flow of rhino horn from South Africa's Kruger National Park to buyers in Asia. Certain species - the rhino being a good example-seem to have gotten caught up in a "human-generated feedback loop" termed the "anthropogenic Allee effect" (the original Allee effect in ecology referred to an unstoppable dwindling of a species once its numbers fall below a certain level): The price of a sought-after species or its parts often shoots up as it becomes increasingly rare, stimulating hunting and driving it into "an extinction vortex" (Courchamp et al. 2006). Unfortunately, just mandating an end to this trade through legal means will be insufficient to stop it. Both the oblivious "demand" of the consumers and the desperate poverty of its providers must be addressed as well. Both ends of the pincers that have the Earth's remaining wild animals in a stranglehold must be dealt with if we are to reduce our future pandemic risk; the longer term goal needs to be transitioning to a path that moves us toward a Biosphere with a more equitable balance of evolved species, substantially restored ecological functionality, and humans accepting a more appropriate and more respectful place within the spectrum of Life on Earth. Since the driving force operating at both ends of the pincers seems to be, increasingly, an economic one, perhaps our collective attention should be directed toward analyzing the whys and wherefores of that particular institution in its present form.

2. We Live Far Outside Our Proper Place within the Biosphere. We seem to have forgotten our evolutionary heritage, disowned our closest relations and lost respect for our place within the Biosphere. We are currently living far, far outside what would be considered an evolutionarily appropriate ecological niche for our species.

Might we now have an "Oh, my God" moment, as we take a good look at ourselves, noticing, as we contemplate taking that next big leap into the Anthropocene, how far we've come over our long course of evolution, as well as how close we may be to the precipice? Life on this planet-its origin and essential nature still largely a mystery to us - has been evolving for more than 3 billion years. Multicellular lifeforms only began appearing in the latter part of the last billion. Early forms of plants and animals, vertebrate and invertebrate, that arose in the Cambrian Explosion of 500 million years ago have descendants that are still with us today, often in complexly elaborated forms developed over the long course of evolution that has them sharing the present with us today. The most severe extinction event in Earth's history occurred about 250 million years ago, possibly triggered by climate warming, but surviving life in this early Biosphere went on to evolve over the Mesozoic era, the "Age of Reptiles." The earliest mammals are believed to have appeared on the scene over a hundred million years ago, but they stayed small and insignificant until the extinction of the dinosaurs, 65 million years ago. It took another 30 million years or so for there to be large-bodied herbivores, specialized carnivores, and mammals inhabiting air and water as well as land, all emerging by the end of the Oligocene epoch, 23 million years ago. The primate order was evolving over this time as well, with monkeys differentiating over the Oligocene and the ape lineage splitting from the Old World monkeys and 
differentiating over the Miocene, which ended a little over 5 million years ago. Our human line is believed to have diverged from its common ancestor with the chimpanzee and the bonobo somewhere between 4 and 6 million years ago, during the Pliocene, and we have been evolving ever since, slowly developing the traits that have made humanity distinctive in particular ways. Our ability to collectively share a symbolic culture that organizes our activities stands out as fundamental (Searle 1995, 2010), giving rise not only to human language but to the institutional structure of our societies. This has given us a great deal of power over our environment, but in the process it set in motion many positive feedback loops that are now threatening the integrity of the Biosphere and dramatically altering the evolution of planetary Life, threatening to knock down its diversity and complexity, perhaps by millions of developmental years. Our species, along with many other sentient beings, will be unlikely to make the cut.

Our "success" at being able to satisfy a multitude of human "preferences" - preferences often induced, and certainly reinforced, by profit-oriented advertising-has led to many of us adopting habits that have us living far, far outside our naturally evolved ecological niche. One obvious way we have done so is our collective ascent up a couple of trophic levels to usurp the role once played by the true carnivores, who rightfully occupy the apex of ecological food webs. As large-bodied primates, our physiology most resembles that of the other great apes, whose diets in the wild are largely vegetarian; the largest consumers of animal material are the chimpanzees, but even then it makes up less than $10 \%$ of their diets, mostly in the form of insects and insect products (Goodall 1986, Milton 1993). We are living far outside our evolved parameters with respect to things like reproductive potential and population densities, tooamong the "ultimate" causes of our present crisis. But when human agency has been intentionally harnessed into working toward goals like stimulating appetites for salt, fat and animal flesh, reinforcing beliefs attributing an elevated status to meat-eaters, and above all making money while supplying the mass-produced "product," the result has been, predictably, untold animal suffering with the proliferation of CAFOs around the globe. These are accelerating deforestation in the tropics with increasing hunter penetration of remaining wildlands and hence wild animal distress and destruction, and increasingly hazardous conditions for human health, the present pandemic being only the latest in a growing series of epidemic zoonoses.

Might we learn to "see ourselves as primates" in these, perhaps the final minutes of our long evolutionary passage (Hawkins 2002, 2020), and finally grasp our appropriate place among our fellow beings? Doing so might even help us to put in perspective the divisions that we draw within our species' own boundaries (Hawkins 1998). These divisions that have us expending precious time and resources fighting among ourselves instead of seeing and accepting that we humans are all members of one species. We could instead be cooperating to set the Biosphere aright once again, or at least start moving together in that direction (Atkins, Sloan Wilson and Hayes 2019, Eirdosh and Hanisch 2020).

\section{References}

Atkins, P., D. Sloan Wilson, and S. Hayes. (2019). Prosocial: Using Evolutionary Science to Build Productive, Equitable, and Collaborative Groups. Oakland: New Harbinger.

Bar-On, Y., R. Phillips, and R. Milo. (2018). The biomass distribution on Earth. PNAS 115 (25), 6506-6511. 
Cincotta, R., J. Wisnewski, and R. Engelman. (2000). Human population in biodiversity hotspots. Nature 404: 990-992.

Courchamp, F., et al. (2006). Rarity value and species extinction: The anthropogenic Allee effect. PLOS Biology 4 (12): e415.

Courchamp, F., et al. (2018). The paradoxical extinction of the most charismatic animals. PLOS Biology 16 (4): e2003997.

Eirdosh, D., and Hanisch, S. (2020). Can the science of Prosocial be a part of evolution education? Evolution: Education and Outreach 13: 5.

Faust, C. L., et al. (2018). Pathogen spillover during land conversion. Ecology Letters 21(4): 471-483.

Feely,E., et al. (2004). Impact of anthropogenic CO2 on the CaCo3 system in the oceans. Science 305 (5682): 362-366

Hannibal, M. E. (2020). A profound plan to save the seas. Science 370 (6516): 538.

Hawkins, R. (1998). Intergroup justice: Taking responsibility for intraspecific and interspecific oppressions. Ethics \& the Environment 3 (1): 1-40.

Hawkins, R. (2002). Seeing ourselves as primates. Ethics \& the Environment 7 (2): 61-103.

Hawkins, R. (2020). Our war against nature: Ontology, cognition, and a constricting paradigm. Chapter 11 in Human Security and World Affairs: Problems and Opportunities (A. and S. Lautensach, eds). U. North British Columbia.

Hubschle, A. (2016). A Game of Horns: Transnational Flows of Rhino Horn. Studies on the Social and Political Constitution of the Economy, Cologne: International Max Planck Research School on the Social and Political Constitution of the Economy.

Koch, P., and A. Barnosky. (2006). Late Quaternary extinctions: State of the debate. Annual Review of Ecology, Evolution, and Systematics 37: 215-250.

Lee, K. (2020). Rethinking global governance to address zoonotic disease risks: Connecting the dots. Animal Sentience 30(19).

Lewis, D. (2020). Deathly silent: Ecologist describes Australian wildfires' deadly aftermath. Nature 577: 304.

Machovina, B., K. Feeley, and W. Ripple. (2015). Biodiversity conservation: The key is reducing meat consumption. Science of the Total Environment 536: 419-431.

Milner-Gulland, E., and E. Bennett. (2003). Wild meat: The bigger picture. Trends in Ecology \& Evolution 18 (7): 351-357.

Milton, K. (1993). Diet and primate evolution. Scientific American 269 (2): 86-93.

Orr, J., et al. (2005). Anthropogenic ocean acidification over the twenty-first century and its impact on calcifying organisms. Nature 437: 681-686.

Peterson, D. (2004). Eating Apes. Photography by Karl Amman. Oakland, CA: U. California Press.

Pickrell, J., and E. Pennisi. (2020). Record U.S. and Australian fires raise fears for many species. Science 370 (6512): 18-19.

Redford, K. (1992). The empty forest. BioScience 42 (6): 412-422.

Ripple, W., et al. (2016). Bushmeat hunting and extinction risk to the world's mammals. Royal Society Open Science 3: 160498.

Ripple, W., et al. (2019). Are we eating the world's megafauna to extinction? Conservation Letters 12:e12627.

Robinson, J., K. Redford, and E. Bennett. (1999). Wildlife harvest in logged tropical forests. Science 284 (5414): 595-596.

Rose, A. (2003). Consuming Nature: A Photo Essay on African Rain Forest Exploitation. Photography by Karl Ammann. Palos Verdes Peninsula, CA: Altisima Press.

Searle, J. (1995). The Construction of Social Reality. New York: The Free Press.

Searle, J. (2010). Making the Social World: The Structure of Human Civilization. Oxford University Press. 
Seibold, S., et al. (2019). Arthropod decline in grasslands and forests is associated with landscape-level drivers. Nature 574: 671-674.

Treves, A; Santiago-Ávila, F. J.; and Lynn, W, S. (2019) Just preservation. Animal Sentience 27(1)

Wiebers, D., \& Feigin, V. (2020). What the COVID-19 crisis is telling humanity. Animal Sentience 30(1). 